La contaminación entre ficción y no-ficción. Big Brother

Analía Becherini

Question/Cuestión, Nro.70, Vol.3, diciembre 2021

ISSN: $1669-6581$

URL de la Revista: https://perio.un/p.edu.ar/ojs/index.php/question/

IICom -FPyCS -UNLP

DOI: https//doi.org/10.24215/16696581e616

\title{
La contaminación entre ficción y no-ficción
}

Big Brother

The Contamination between fiction and non-fiction

Big Brother

Analía Becherini

Argentina

analiabecherini@gmail.com

https://orcid.org/0000-0001-6940-4597 


\title{
Resumen
}

Presento la mirada que tiene Eliseo Verón del reality show Big Brother en el marco de su análisis de la televisión. Posteriormente, mostro la postura de Byung-Chul Han y su mirada del Big Brother amable. Esta postura está enmarcada en una interpretación de las redes sociales y el Big Data como un nuevo tipo de Big Brother promotor de la libertad.

Palabras clave: big brother; semiótica; redes sociales

\begin{abstract}
I present the look that Eliseo Verón has from the reality show Big Brother in the framework of his analysis of television. Afterwards, he showed Byung-Chul Han's posture and his kind Big Brother gaze. This position is framed in an interpretation of social networks and Big Data as a new type of Big Brother promoter of freedom.
\end{abstract}

Key words: Big Brother; semiotics; social media

\section{Introducción}

La idea de denominar Big Brother a un formato de reality show tiene estrecha relación con la obra de Orwell llamada 1984 publicada en 1949. En dicha novela uno de los personajes es una suerte de líder omnisciente y totalitario: Big Brother. Para crear este personaje, Orwell se inspiró en líderes que se caracterizaron por provocar miedo y por educar a la población mediante la utilización de propaganda gubernamental intensiva en valores, donde pensar libre e individualmente era visto como una traición a la sociedad.

En la primera parte de este trabajo presentaremos la mirada que tiene Eliseo Verón del reality show Big Brother en el marco de su análisis de la televisión. Específicamente, nos hemos apoyado en el texto "La semiosis social, 2".

Posteriormente, mostramos la postura de Byung-Chul Han y su mirada del Big Brother amable. Esta postura está enmarcada en una interpretación de las redes sociales y el Big Data como un nuevo tipo de Big Brother promotor de la libertad. Nos apoyamos en su libro "Psicopolítica". 
Finalmente, realizaremos una suerte de conclusión.

\section{Big Brother en Eliseo Verón}

Según Eliseo Verón, el dispositivo de la televisión, como sus usos, se encuentra en un continuo cambio. Realizaremos un recorrido por su evolución y nos detendremos en los realities.

Antes de continuar, es importante hacer referencia a algunos conceptos. Se denomina metatelevisión a aquello que ocurre a la vez, "junto a" o "después de" los programas de televisión. Los programas que se encuadran dentro de esta definición son aquellos que utilizan los productos propios de la televisión para la creación de sus contenidos: los programas de recortes o zapping, los realities y los magazines. En dichos programas se destacan la autorreferencialidad, la intertextualidad y la mezcla de géneros. El término metatelevisión se refiere a la producción televisiva propia del cambio de milenio. Vale destacar que la mezcla de géneros concierne también a la contaminación entre ficción y no ficción (Verón, 2013).

El conjunto de la televisión del siglo XXI es cada vez más autorreferencial: la metatelevisión se caracteriza por hablar incesantemente de ella misma. Con el término «metatelevisión» Olson se refiere a la capacidad del espectador de identificar el artificio televisivo, la intertextualidad y la estructura reflexiva del medio (Olson, 1987).

La televisión histórica comenzó a instalarse en el mundo, según Verón, después de la Segunda Guerra Mundial. Vertiginosamente se convirtió en el fenómeno más importante de la mediatización de la segunda mitad del siglo XX. Vale destacar que, a partir de la televisión histórica, la dimensión indicial de la semiosis se organiza en este caso por el contacto ocular. Dicho contacto pasó a ser central en el vínculo entre los actores y los medios masivos. La transmisión de datos es recibida por todos los dispositivos en una red. El envío de información a todos los dispositivos que se encuentren conectados en la misma red dominó el mundo de la mediatización de la televisión histórica. En ese momento la característica más importante de la televisión era el contacto ocular con el destinatario. Esto es, la mirada del actor en pantalla que hace sentir al televidente que le habla a él, que se dirige a él. El eje es la mirada: esas personas que están en la televisión me hablan a mí (Verón, 2013). 
La primera etapa, denominada por algunos autores como paleotelevisión, se extiende desde la instalación de la televisión en la sociedad hasta finales de los setenta (1950-1979). Aquí el interpretante esencial del discurso televisivo fue el contexto sociocultural que se encontraba por afuera de lo televisivo. En esta etapa no se discutía la transparencia, sino que era un contrato más bien enciclopedista complementario. En el ámbito del paradigma sistémico relacional, la complementariedad describe un patrón de relación donde el comportamiento y las aspiraciones de los individuos o del grupo difieren y se complementan recíprocamente. Esta modalidad relacional, si es vivida armónicamente, permite establecer un equilibrio dinámico y funcional. Por tanto, la televisión mostraba e informaba sobre el mundo (Bateson, 1973). Comprendiendo dicha complementariedad, según Verón, se puede observar que el fenómeno de la televisión en la primera etapa, fue semejante tanto en Estados Unidos -con un sistema privado-, como en los países europeos -con regímenes de monopolio del Estado-. Vale destacar, que en esta primera etapa, los ciudadanos-televidentes y el colectivo de ciudadanoselectores tienden a superponerse, cuestión que se fue disociando cada vez más (Verón, 2013).

Los ochenta son considerados por Eliseo Verón como años de transición de la televisión pública a la privada. Además, en estos años se multiplica la oferta de televisión por cable. Ahora bien, en la segunda etapa, también conocida como neotelevisión, la televisión se convierte en su propio interpretante. Se extiende desde comienzos de los años noventa hasta fines del siglo XX. Aquí la televisión comienza a multiplicar y diversificar la oferta de programación. Puntualmente, lo que nos ocupa en esta oportunidad es la tercera etapa que se inicia con el cambio de milenio.

En el año 2001 comienzan los realily shows. El interpretante dominante es una configuración compleja de colectivos externos a la televisión con la característica de que son extraídos de la realidad. El reality show es una suerte de híbrido que combina lo "real", que es todo lo que no forma parte del mundo televisivo, y la puesta en escena de esa "realidad" que se trae a la pantalla. Por tanto, todo lo "real" que se toma del territorio, se transforma en un show cuando aparece en la pantalla. En este sentido, la realidad no se opone a la ficción sino a la televisión como institución, y los reality shows son una puesta en escena de la diferencia entre vida cotidiana y televisión (Verón, 2013). 
El componente esencial del formato de Big Brother tiene que ver con las reglas explicitas del funcionamiento interno (enmarcado por el encierro) y su relación con el exterior. Son personas seleccionadas de la realidad que representan la forma de vida cotidiana y deben convivir dentro de una suerte de casa llena de cámaras que los filma las 24 horas. Según Verón, la noción de casa le da mayor verosimilitud a la lógica de interacción por parte de los participantes que compiten por un importante beneficio económico. Los participantes votan en forma secreta a quién eligen para abandonar la casa. Pero esto no es todo, ya que la intervención del público por medio del voto para que alguno de los participantes suma complejidad a las estrategias que debe plantearse cada participante. Por un lado, se destaca la creciente familiaridad de la audiencia con los participantes como si fuera una suerte de telenovela. Por el otro, el sometimiento sistemático a la doble evaluación por parte de los participantes.

Los participantes deben contemplar dos estrategias: una hacia adentro de la casa y otra hacia la mirada de los televidentes. Aquí podemos observar el proceso de mediatización de la vida cotidiana en la que se incorpora a los televidentes con su voto. Esta excepcionalidad logra transformar los regímenes icónico -a nivel del enunciado- e indicial -a nivel de la enunciación- de la comunicación, y se produce una ruptura de escala. Esto es, la televisión altera la escala cuando muestra un gesto de cariño dentro de la casa entre dos participantes y se genera la ruptura de escala cuando millones de televidentes acceden a dicho gesto. La televisión es un dispositivo que en esta fase logra visibilizar la ruptura de escala (Verón, 2013).

\section{El Big Brother amable de Byung-Chul Han}

La web 2.0 en la que los usuarios pueden participar como productores de sentido vuelve a alterar la escala y surgen niveles de complejidad que el Big Data visibiliza. Esto es, un caudal inconmensurable de patrones repetitivos dentro de las publicaciones que los usuarios de la web 2.0 realizan en forma prerreflexiva. Las tecnologías de la web 3.0, como programas inteligentes, utilizan datos semánticos que proporcionan los usuarios. Han posiciona a la web 2.0 como una serie de técnicas de dominación del capitalismo neoliberal. La psicopolítica es, según Han, aquel sistema de dominación en el que se oprime amablemente a través del teléfono inteligente o Smartphone (Han, 2014). 
En este sistema, el sujeto sometido no es consciente ya que la eficacia del psicopoder radica en que el individuo se cree libre, cuando en realidad es el sistema el que está explotando su libertad. La psicopolítica se sirve del Big Data el cual, como un Big Brother digital, se apodera de los datos que los individuos le entregan de forma efusiva y voluntaria. Dicho instrumento permite hacer pronósticos sobre el comportamiento de las personas y condicionarlas a un nivel prerreflexivo (inconsciente). La expresión libre y la hipercomunicación que se difunden por la red, se convierten en control y vigilancia totales, conduciendo a una auténtica crisis de la libertad. En lugar de confesiones extraídas por medio de la tortura, los usuarios son animados al desnudamiento voluntario: muestran lo que piensan, lo que hacen, lo que les gusta, lo que compran, etc. Esta excepcionalidad logra transformar los regímenes icónico -a nivel del enunciado- e indicial -a nivel de la enunciación- de la comunicación y se produce una ruptura de escala al igual que la televisión en su tercera fase. Este poder inteligente podría detectar incluso patrones de comportamiento del inconsciente colectivo que otorgarían a la psicopolítica un control ilimitado. Nuestro futuro dependerá de que seamos capaces de servirnos de lo inservible, de la singularidad no cuantificable y de la idiotez -dice incluso- de quien no participa ni comparte (Han, 2014).

Vale destacar que a través del uso compulsivo de las redes sociales, la emoción se presenta como el libre despliegue de la personalidad. Por tanto, la subjetividad genera necesidades que son estimuladas por la web semántica que se basa en los patrones de gusto estandarizados por el Big Data. Esto es, se estimula el consumo utilizando mecanismos emocionales. El impulso está regulado por el sistema límbico y la psicopolítica neoliberal opera a un nivel instintivo para regular las acciones y controlarlas. Los usuarios de las redes sociales, como los participantes de Big Brother, buscan la gratificación instantánea, el me gusta y la aprobación de los seguidores (Han, 2014).

Según Han, la inteligencia de datos resulta ser más eficiente que el panóptico de Bentham ya que se logra un estado permanente de visibilidad. Esto garantizaba el funcionamiento automático del poder, sin que ese poder se estuviera ejerciendo de manera efectiva en cada momento, puesto que el prisionero no podía saber cuándo se le vigilaba y cuándo no. Pero la inteligencia de datos elimina los puntos ciegos, posibilita la vigilancia total e incluso el control psicopolítico de los usuarios. La web 2.0 registra la vida de los individuos. 
Según Han, la capacidad de control de la psicopolítica digital pone en grave riesgo la libertad. Es incluso capaz de adelantarse a los deseos inconscientes. En la actualidad se comercializan dichos datos personales con todo tipo de fines. Los usuarios continúan comunicando todos sus pensamientos y sentimientos en las redes sociales y dando cuenta de sus movimientos. En resumen, el poder no se impone, sino que se estabiliza de una manera amable, invisible e inatacable.

Conclusiones

Podemos pensar que la lógica lúdica de Big Brother genera que los participantes contemplen dos estrategias: una hacia adentro de la casa y otra hacia la mirada de los televidentes. Podemos pensar que ocurre un fenómeno parecido cuando los usuarios deben mostrar hacia el exterior sus biografías.

Una de las repercusiones más contundentes de la televisión-realidad ha sido Big Brother bajo la lógica de la transparencia de lo que se proclama como "la vida en directo". Los denominados reality shows introducen un elemento que dramatiza en clave emocional la vida cotidiana. Producto de la fusión de los mecanismos propios del género concurso con el seguimiento telenovelesco de las vidas de los participantes. En Big Brother los concursantes deben señalar a sus compañeros para que sean expulsados, pero es el público, a través de votación telefónica, quien finalmente decide la expulsión de los nominados. El concursante ganador, el último en salir de la casa, obtiene un premio económico elevado.

En el caso del uso compulsivo de las redes sociales la emoción se presenta como el libre despliegue de la personalidad. La subjetividad genera necesidades que son estimuladas por la web semántica que se basa en los patrones de gusto estandarizados por el Big Data. Esto es, se estimula el consumo utilizando mecanismos emocionales. El impulso está regulado por el sistema límbico y la psicopolítica neoliberal opera a un nivel instintivo para regular las acciones y controlarla. Los usuarios de las redes sociales, como los participantes de Big Brother buscan la gratificación instantánea, el me gusta y la aprobación de los seguidores. En Psicopolítica, Han, critica al Big Data que tiene a todos los usuarios vigilados y controlados por una falsa libertad. La libertad de expresión o de actuación es todo un método creado para excluir, aislar y dominar. Del mismo modo actúa la moderna tendencia a comunicarnos a nivel 
planetario: es una herramienta del sistema. Nos incita y seduce para que nos desnudemos, para que nos expresemos cuanto más mejor con el fin de conocernos perfectamente y así poder manipularnos a su antojo: nos ha dicho que somos libres, pero en realidad se ha valido de esa idea para que hagamos lo que él quiere.

\section{Referencias bibliográficas}

Bateson, G. (1973). Pasos hacia una ecología de la mente. Ed. Carlos Lohlé, Bs. As., 1985. Bladé, R. (2006). CSI: tropical y urbanita, TVmanía. La Vanguardia (02/08-09-06). Carlón, M. (2005). Metatelevisión: un giro metadiscursivo de la televisión argentina, en LACALLE, R. (Coord.). De Signis 7/8. Los formatos de la televisión. Gedisa, Barcelona; 147158.

Carlón, M. (2006). De lo cinematográfico a lo televisivo. Metatelevisión, lenguaje y temporalidad. Buenos Aires: La Crujía. CARO, A. (2007). Intermediación publicitaria. XII Congreso Internacional de la Asociación Española de Semiótica Interme diaciones (en prensa). Fernandez, J.L. (2008). La construcción de lo radiofónico: modos de producción de la novedad discursiva. En: La construcción de lo radiofónico (9-74), Buenos Aires: Icrj 'La crujía. González Requena, J. (1992). El discurso televisivo: espectáculo de la posmodernidad. Madrid: Cátedra.

Hernando, D. (2003). CSI: Confidencial. Palma de Mallorca: Dol - men. Han, B. (2014). Psicopolitica. Neoliberalismo y nuevas técnicas de poder. Barcelona: Pensamiento Herder. Imbert, G. (2003). El zoo visual. De la televisión espectacular a la televisión especular. Barcelona: Gedisa. IMBERT, G. (2008). El transformismo televisivo. Postelevisión e imaginarios sociales.

Madrid:

Cátedra. Jancovich, N. \& LYONS (2003). Quality popular television. Cult TV, the industry and fans. London: British Institute Kirk, G.S. (1973). El mito. Su significado y funciones en las distintas culturas. Barcelona: Barral Editores.

Metz, C. (1971). "Spécificite / non-spécificite": relativité d 'un partage maintenu. En:Langage et cinema (157-189), Paris: Langue et langage Larousse 
Metz, C. (1991) L 'enonciation anthropoide. En: L 'enonciation impersonnelle ou le site du film (11-36), Paris: Méridiens Klincksieck.

Olson Scott, R. (1987). Meta-television: Popular Postmodernism. Critical Studies in Mass Communication,

Olson Scott, R. (1990). Reading Meta-Television: A New Model for Reader-Response Criticism. Annual Meeting of the Internatio - nal Communication Association (40th, Dublin). ERIC, Edu cational Resources Information

Center.

Traversa, O. (2017). Christian Metz and the mediatisation. ESSACHESS. Journal for Communication Studies Vol. 10, no. 1(19) elSSN 1775-352X. Verón, E. (2013). La semiosis social, 2: Ideas, momentos, interpretantes. -1ed.- Bs. As. Paidos. 